\title{
The role of collective efficacy and co-regulation in medical students' performance in small group contexts
}

\section{Jihyun $\mathrm{Si}$}

Department of Medical Education, Dong-A University College of Medicine, Busan, Korea

Purpose: This study investigated the role of collective efficacy and co-regulation in terms of students' performance during small group projects in a medical research program. The effect of collective efficacy in student performance was expected to be mediated by co-regulation.

Methods: A total of 50 students who enrolled in a medical research program worked on their medical research project in small groups over a period of 9 weeks. After they had submitted their final research project reports as groups at the end of the course, the collective efficacy and co-regulation surveys were conducted online.

Results: The mediation model was significant and explained $26.61 \%$ of the variance in student performance. The total effect of collective efficacy on student performance was significant and the indirect effect through co-regulation was also significant.

Conclusion: These results suggest that collective efficacy influenced student performance through co-regulation in group learning contexts. Considering the fact that more and more collaborative learning now occurs in medical education, the result of this study can provide significant insights for enhancing students' performance in small group contexts.

Key Words: Collective efficacy, Co-regulation, Collaborative learning, Mediating effect, Medical education

\section{Introduction}

Over recent decades, the importance of collaborative learning has increased alongside the growing need for student-centered learning environments [1]. Collaborative learning involves small group activities and often occurs in the form of problem-based learning or team-based learning in medical education contexts. In collaborative learning, students are mutually engaged in a coordinated effort to solve a problem together and to maximize both their own and each other' s learning [2].
Previous research has reported that collaborative learning has positive effects on students' academic performance [2]. However, merely placing students in a group does not guarantee that such social forms of learning will prove beneficial. Successful collaborative learning is facilitated through the process of interacting with others [3]. Therefore, group level variables that lead to the most favorable learning outcomes, such as collective efficacy and co-regulation, need to be concerned to understand the nature and emergence of productive interactions in collaborative learning.

Collective efficacy refers to a perceived belief in the
Received: January 28, 2020 • Revised: March 6, 2020 • Accepted: March 16, 2020 Corresponding Author: Jihyun Si (https://orcid.org/0000-0002-4782-6104) Department of Medical Education, Dong-A University College of Medicine, 32 Daesingongwon-ro, Seo-gu, Busan 49201, Korea

Tel: +82.51.240.2617 Fax:+82.51.240.2617 email: jenny0306@dau.ac.kr
Korean J Med Educ 2020 Jun; 32(2): 143-149.

https://doi.org/10.3946/kjme.2020.162

eISSN: 2005-7288

(C) The Korean Society of Medical Education. All rights reserved. This is an open-access article distributed under the terms of the Creative Commons Attribution Non-Commercial License (http:// creativecommons.org/licenses/by-nc/3.0/), which permits unrestricted non-commercial use, distribution, and reproduction in any medium, provided the original work is properly cited. 
performance capability of a group as a whole [4]. This is in contrast to self-efficacy, which involves an individual belief about his or her capacity in performing a specific task individually [4]. Self-efficacy, one of the most powerful components of motivation, is generally accepted as a positive predictor of student performance in educational settings [4]. Likewise, the meta-analysis of Stajkovic et al. [5] in collaborative learning indicates a significant positive relationship between collective efficacy and group performance, particularly when group goal attainment requires a significant interdependent effort among group members, such as complex authentic problem solving.

Co-regulation refers to interactions between two or more peers that coordinate their self-regulated learning processes in collaborative learning [3]. Self-regulation refers to metacognitive, motivational, and behavioral processes which individuals use to direct and control their learning, and this has been shown to relate positively to students' performance [6]. In group learning contexts, a similar result is expected regarding $\mathrm{co}^{-}$ regulation, as successful collaborative learning is facilitated by a group's coordinated and co-regulated engagement to build and maintain a shared understanding of a problem. Zheng and Huang [7] have shown empirically that the co-regulated strategy can predict group performance to a high degree. However, research exploring the impact of co-regulation on students' performance is a recent development, meaning more empirical research is necessary in order to understand the role of co-regulation in student performance in collaborative learning contexts.

Self-efficacy belief affects students' regulatory process [8]. Therefore, collective efficacy is expected to have an influence in co-regulatory processes. Knowledge of regulated strategies on its own cannot promote learning. Students should be first motivated to use regulated strategies. Thus, these variables may work together to influence students' performance, but the mechanism through which collective efficiency and co-regulation may be related to each other in facilitating students' performance has not been specified in existing research.

Self-efficacy and self-regulated learning are variables that have often been examined in the context of medical education [8-10], but their group level counterparts have almost not been applied to this context. Thus, this study investigated the role of collective efficacy and co- $^{-}$ regulation in terms of students' performance during small group projects in a medical research program. As motivation is a precursor for students to use regulatory strategies, it is predicted that the effect of collective efficacy on students' performance will be mediated by co-regulation. Given the increasing popularity of group approaches to learning in medical education fields, the results of this study can provide significant insights for enhancing students' performance in small group or collaborative learning contexts.

\section{Methods}

\section{Participants and procedure}

Fifty second-year medical students enrolled in "Scientific Thinking and Medical Research" at a university were invited to participate in this study. Among them, the six students who did not complete the entire survey were excluded, leaving 44 students (29 males and 15 females). In the class, they were divided into 10 groups of five and collaboratively worked on their medical research projects over a period of 9 weeks. After they had submitted their final research project reports as groups at the end of the course, the collective efficacy and co-regulation surveys, including name, 
gender, and student's numbers (in total 26 items) were conducted online. This study was approved by the Institutional Review Board of Dong-A University (IRB approval no., 2-1040709-AB-N-01-201911-BR-016-04).

\section{Collaborative learning}

"Scientific Thinking and Medical Research" was designed as project-based learning whereby the students conducted their own authentic medical research collaboratively in groups under the supervision of a professor assigned to each group. The course was a three-credit course and the students met twice a week during a 15-week semester. Each class meeting was 120 minutes long. In terms of the class activities, for the first 5 weeks, the students listened to lectures concerning how to conduct medical research. Then, during the rest weeks, they conducted their own research through constructive investigations from defining a research question to developing answers to their chosen question (final research report). The project was student-driven to a significant degree, with the professors playing a facilitating role.

\section{Students' performance assessment}

Students' performance scores included both group and individual scores (in total=90). The group scores included their research proposal $(n=30)$ and final research proposal $(\mathrm{n}=40)$ scores, while the individual scores included individual contribution $(\mathrm{n}=10)$, self-assessment $(n=5)$, and peer assessment $(n=5)$. Student performance was scored by 10 participating professors using scoring rubrics, with the mean scores given as the final scores. The self-assessment and peer-assessment scores were given by the students themselves and their group members, respectively.

\section{Tools}

The collective efficacy scale was derived from the self-efficacy items of the Motivated Strategies for Learning Questionnaire, developed by Pintrich and De Groot [11], and then revised to the group level, as in a prior study conducted by Wang and Lin [1]. The scale consisted of nine items, and its Cronbach's $\alpha$ in this study was 0.94 . The co-regulation scale was also revised from the self-regulated learning strategy scale developed by Zimmerman and Martinez-Pons [12] as in the research of DiDonate [6]. It was changed to a $\mathrm{co}^{-}$ regulation scale by replacing "I" to "we." The $\mathrm{co}^{-}$ regulation scale contained 13 items, excluding one item which was not suitable for collaborative learning situations, and its Cronbach's $\alpha$ in this study was 0.93 . Both questionnaires used a 7-point Likert scale ranging from 1 (not at all) to 7 (very true).

\section{Analysis}

Descriptive statistics and correlation analyses were conducted using the IBM SPSS ver. 24.0 (IBM Corp., Armonk, USA) in order to examine the relation among the variables. The mediating effect of co-regulation was assessed using the PROCESS macro for SPSS ver. 3.4 (http://processmacro.org/index.html) [13] after applying model 4 with 5,000 bootstrap samples. PROCESS macro is a widely used tool throughout the social and health science field for estimating direct and indirect effects. In terms of testing indirect effects, if the 95\% confidence interval (CI) includes 0 , the indirect effect was not significant, while if 0 was not in the interval, the indirect effect was statistically significant [13]. The significant level for other statistical analyses was 0.05. 


\section{Results}

\section{The results of correlation and descriptive statistics.}

The results of correlation and descriptive statistics of the variables are presented in Table 1. The correlations among collective efficacy, co-regulation, and student performance were all significant and positive. The correlation coefficient between co-regulation and student performance was the highest $(r=0.468)$. The means of collective efficacy, co-regulation, and student performance were 44.43, 66.21, and 69.75, respectively.

\section{The results of mediation analysis}

The question of whether collective efficacy influences student performance through co-regulation was examined and the results are shown in Table 2. The mediation model was significant $(F[2,41]=7.4333$, $\mathrm{p}=0.0018$ ) and explained $26.61 \%$ of the variance in student performance. Collective efficiency has a significant impact on co-regulation ( $\beta=0.5270, p=0.0042$ ), and co-regulation also has a significant impact on student performance $(\beta=0.1431, p=0.0175)$. In addition, as seen in Table 3, the total effect of collective efficacy on student performance $(\beta=0.1923, p=0.0079)$ was significant, but the direct effect of collective efficacy was reduced to the insignificant level ( $\beta=0.1169$, $\mathrm{p}=0.1115)$. The indirect effect through co-regulation was significant $(\beta=0.0754 ; 95 \% \mathrm{CI}, 0.0142-0.1700$ ). Therefore, co-regulation is deemed to be a mediator of the relationship between collective efficacy and student performance.

\begin{tabular}{llll}
\hline Table 1. Correlation and Descriptive Statistics & & & \\
\hline & \multicolumn{1}{c}{1} & \multicolumn{1}{c}{3} \\
\hline 1. Collective efficacy & 1 & 1 & \\
2. Co-regulation & $0.424^{*}$ & $0.468^{*}$ & 1 \\
3. Student performance & $0.395^{*}$ & $66.21 \pm 8.99$ & $69.75 \pm 3.52$ \\
Mean \pm standard deviation & $44.43 \pm 7.23$ & \\
\hline
\end{tabular}

${ }^{*} \mathrm{p}<0.05$.

Table 2. The Mediation Model Analysis

\begin{tabular}{lrcccc}
\hline & $\beta$ & Standard error & t-value & p-value & Confidence interval \\
\hline Co-regulation & & & & & \\
$\quad$ Constant & 42.7879 & 7.8224 & 5.4699 & 0.0000 & 27.0015 to 58.5743 \\
$\quad$ Collective efficacy & 0.5270 & 0.1738 & 3.0320 & 0.0042 & 0.1762 to 0.8778 \\
Student performance & & & & & \\
$\quad$ Constant & 55.0758 & 3.8330 & 14.3687 & 0.000 & 47.3348 to 62.8169 \\
$\quad$ Co-regulation & 0.1431 & 0.0578 & 2.4770 & 0.0175 & 0.0264 to 0.2598 \\
$\quad$ Collective efficacy & 0.1169 & 0.0719 & 1.6268 & 0.1115 & -0.0282 to 0.2620 \\
\hline
\end{tabular}

Table 3. Verification of the Mediating Effect

\begin{tabular}{lccr}
\hline & $\beta$ & Standard error & Confidence interval \\
\hline Total effect & 0.1923 & 0.0690 & 0.0532 to 0.3315 \\
Direct effect & 0.1169 & 0.0719 & -0.0282 to 0.2620 \\
Indirect effect & 0.0754 & 0.0405 & 0.0142 to 0.1700 \\
\hline
\end{tabular}




\section{Discussion}

Because more and more collaborative learning now occurs in medical education, and even in clinical skill acquisition, in which collaborative learning is usually not very common $[14,15]$, identifying how productive forms of collective thinking and co-construction of understating arise from small group activities is critical. However, very limited attention has been paid to this important issue. Thus, this study examined the role of collective efficacy and co-regulation in terms of student performance in the context of a medical research program where students worked collaboratively in small groups. The results indicated that collective efficacy and co-regulation explained $26.61 \%$ of the variance in student performance, and, as seen in Fig. 1, the effect of collective efficacy on students' performance is mediated by co-regulation.

Collective efficacy only indirectly affected student performance. Thus, collective efficacy can be said to influence student performance through co-regulation in group learning contexts. These results are consistent with previous studies showing that motivation is a prerequisite of using regulated strategies and has a positive impact on student performance $[4,5,11]$.

Successful collaborative learning is inherently as- sociated with a group's co-regulated capabilities in group activities, but empirical research showing the relation between co-regulation and student performance is rare. This study adds empirical evidence regarding the positive impact of co-regulation on student performance in collaborative learning. This result is in line with that of a study by Volet et al. [3], who demonstrated that effective co-regulated strategies help learners to build productive and meaningful knowledge.

This study showed the positive relationship between collective efficacy and co-regulation in medical education contexts. Demirören et al. [8] demonstrated a positive relationship between self-efficacy and selfregulated learning skills in the context of problem-based learning in medical education. Although their research did not directly indicate a correlation between the group level variables, in the sense that both studies empirically show a correlation between motivation and regulatory processes, they show similar results.

The results of this study have several important implications. This study shows the mechanism through which collective efficiency and co-regulation are related to each other in facilitating students' performance. Explicit instructional intervention for co-regulated strategies, such as instructing or demonstrating how to set learning goals, monitor, or evaluate their work while working in groups, may produce promising results in

Fig. 1. Moderating Effect of Co-regulation in the Relationship between Collective Efficacy and Student Performance
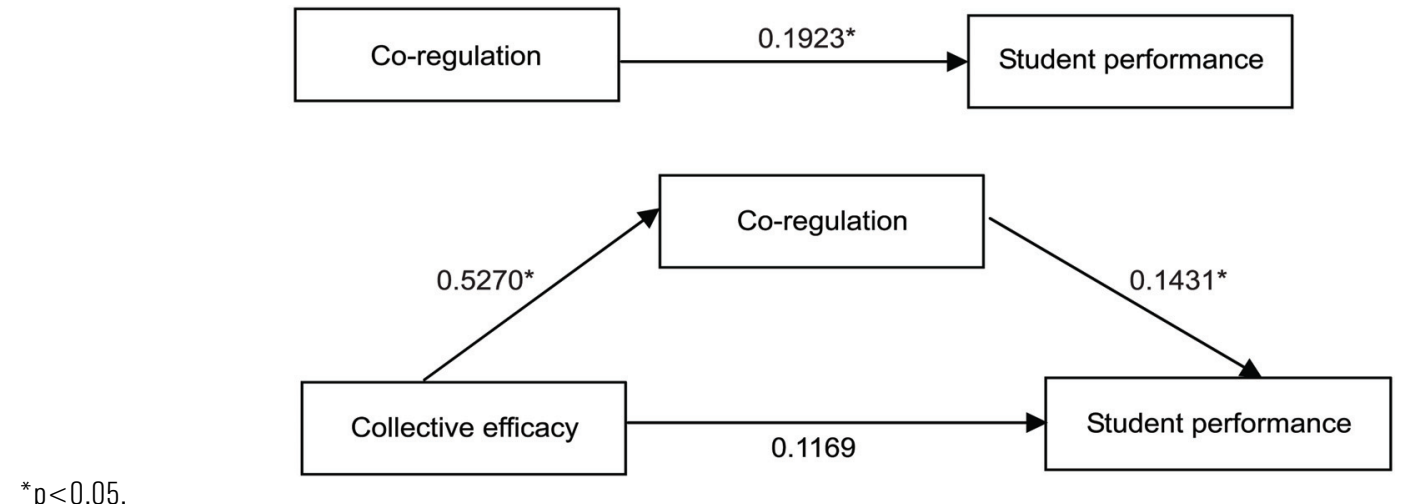

${ }^{*} \mathrm{p}<0.05$. 
terms of student performance in much the same way explicit self-regulation intervention programs did [6]. In addition, collective efficacy is also an important target of effective collaborative learning. Collective efficacy is built on previous experience of collaborative learning, so successful group learning experience plays an important role in constructing collective efficacy [4]. For this, the instructors need to first ensure that learners are aware of the importance of productive interactions before they are involved in collaborative learning. In addition, it is also critical that they monitor group activity and provide feedback timely in order to promote successful collaborative learning [1]. Lastly, the research indicated that when students set clear, specific, and reasonable goals, they are more motivated to perform. By contrast, goals that are too difficult or broad lead to frustration, resulting in a degradation of their efficacy $[9,16]$. Thus, helping students set clear, specific, and reasonable goals, or, if necessary, intermediate goals (for example, writing a research question or finding related papers) should be promoted as an alternative to setting only one final goal (conducting research) in order to ensure effective collaborative learning experiences.

There are some limits to this study. Causal inference requires control of the temporal ordering of events, but, in this study, the two variables were measured at the same time although this seems to be a widespread issue regarding this type of research. In addition, this study was conducted with relatively a small number of subjects from only one medical school. It would be useful, therefore, to perform future studies using a longitudinal design with a larger number of subjects from a more diverse range of backgrounds.

\section{ORCID:}

Jihyun Si: https://orcid.org/0000-0002-4782-6104
Acknowledgements: None.

Funding: This work was supported by the Dong-A University research fund.

Conflicts of interest: No potential conflict of interest relevant to this article was reported.

Author contributions: All work was done by Jihyun Si.

\section{References}

1. Wang SL, Lin SS. The effects of group composition of self-efficacy and collective efficacy on computersupported collaborative learning. Comput Hum Behav. 2007;23(5):2256-2268.

2. Roschelle J, Teasley SD. The construction of shared knowledge in collaborative problem solving. In: O’Malley C, ed. Computer Supported Collaborative Learning. Berlin, Germany: Springer; 1995:69-97.

3. Volet S, Summers M, Thurman J. High-level coregulation in collaborative learning: how does it emerge and how is it sustained? Learn Instr. 2009;19(2): 128-143.

4. Bandura A. Exercise of human agency through collective efficacy. Curr Dir Psychol Sci. 2000;9(3):75-78.

5. Stajkovic AD, Lee D, Nyberg AJ. Collective efficacy, group potency, and group performance: meta-analyses of their relationships, and test of a mediation model. J Appl Psychol. 2009;94(3):814-828.

6. DiDonato NC. Effective self-and co-regulation in collaborative learning groups: an analysis of how students regulate problem solving of authentic interdisciplinary tasks. Instr Sci. 2013;41(1):25-47.

7. Zheng L, Huang R. The effects of sentiments and coregulation on group performance in computer supported collaborative learning. Internet High Educ. 2016;28: 59-67.

8. Demirören M, Turan S, Öztuna D. Medical students' 
self-efficacy in problem-based learning and its relationship with self-regulated learning. Med Educ Online. 2016;21:30049.

9. Artino AR Jr. Academic self-efficacy: from educational theory to instructional practice: version 2. Perspect Med Educ. 2012;1(2):76-85.

10. Van Houten-Schat MA, Berkhout JJ, van Dijk N, Endedijk MD, Jaarsma AD, Diemers AD. Self-regulated learning in the clinical context: a systematic review. Med Educ. 2018;52(10):1008-1015.

11. Pintrich PR, De Groot EV. Motivational and selfregulated learning components of classroom academic performance. J Educ Psychol. 1990;82(1):33-40.

12. Zimmerman BJ, Martinez-Pons M. Student differences in self-regulated learning: relating grade, sex, and giftedness to self-efficacy and strategy use. J Educ Psychol. 1990; $82(1): 51-59$.

13. Hayes AF. Beyond Baron and Kenny: statistical mediation analysis in the new millennium. Commun Monogr. 2009;76(4):408-420.

14. Tolsgaard MG, Kulasegaram KM, Ringsted CV. Collaborative learning of clinical skills in health professions education: the why, how, when and for whom. Med Educ. 2016;50(1):69-78.

15. Edmunds S, Brown G. Effective small group learning: AMEE guide no. 48. Med Teach. 2010;32(9):715-726.

16. Si J. Effects of tutor performance and collective efficacy on learner performance and satisfaction in medical problem-based learning. Korean J Educ Methodol Stud. 2016;28(1):103-123. 